\title{
Changes in stability conditions of clay slopes due to leaching: a case study
}

\author{
Mahdi Madadzadeh Toulegilan ${ }^{1} \cdot$ Reza Jamshidi Chenari $^{1}$ [D $\cdot$ Mir Ahmad Lashteh Neshaei ${ }^{1} \cdot$ Akbar Forghani $^{2}$
}

Received: 17 February 2020 / Accepted: 28 April 2020 / Published online: 7 May 2020

(c) Springer Nature Switzerland AG 2020

\begin{abstract}
Leaching through natural soil deposits manifests in form of modifications in mechanical parameters of the host soil. One of the outcomes of strength reduction in soils due to leaching is slope instability which is exhibited in the form of sliding. In this study, a series of chemical, physical and mechanical tests have been carried out to investigate the effect of leaching on the stability of a clay slope in north of Iran. Results show that leaching removes the soluble salts from the soil, leaving porous and unstable structure. Leaching causes reduction of the mechanical properties of the host soil including deformation and shear strength parameters in drained and undrained conditions. Results of the laboratory tests revealed that leaching has given rise to more than $30 \%$ reduction in the plasticity index, $10 \%$ decrease in the dry unit weight and $45 \%$ decline of the unconfined compressive strength of the host soil. The leaching-induced diminution of the mechanical performance of the host soil is geared to have some slope instability implications by exhibiting a maximum of $50 \%$ reduction in the slop stability safety factor.
\end{abstract}

Keywords Slope stability $\cdot$ Leaching $\cdot$ Salt $\cdot$ Shear strength $\cdot$ Clay

\section{Introduction}

So far, a few researches have been devoted to the effect of salts on the physical and geotechnical behavior of soils $[1,2]$. Leaching, ion exchange, post-depositional change in pore fluid chemistry and removal of fine particles from the soil skeleton can result from the percolation of different fluids through a deposit. This may cause marked changes in the forces between colloidal particles [3]. In other words, leaching causes salt reduction or removal from the soil structure which in effect reduces the electrical conductivity $(E C)$ of the saturated soil $[4,5]$.

Ismael [5] carried out laboratory and field leaching tests on a gypsiferous sandy silt soil. He studied on the Persian Gulf coastal saline soil, considered to be $M L$ according to the unified classification system and containing salts such as gypsum and anidride in its structure. Results indicate that leaching has resulted in increased permeability, void ratio, and compressibility, and a reduction in the pre-consolidation pressure. The triaxial test results showed a decrease in the drained strength parameters due to the leaching. Field leaching resulted in reduction in the dynamic cone penetration resistance [5]. Guarniery et al. [2] conducted leaching tests on two different Italian soils and showed that the salination action greatly increased liquid limit and shear resistance [2]. Sridharan et al. [6] showed that the influence of fluoride on montmorillonites by the aluminum ion extraction from the clay lattice structure results in reduction of the liquid limit and specific gravity and increase of the void ratio for bentonite and montmorillonite clays. Lebron et al. [7] evaluated the calcareous

$\triangle$ Reza Jamshidi Chenari, jamshidi_reza@guilan.ac.ir; Mahdi Madadzadeh Toulegilan, mehdi.madadzadeh@yahoo.com; Mir Ahmad Lashteh Neshaei, maln@guilan.ac.ir; Akbar Forghani, forghani@guilan.ac.ir|'Department of Civil Engineering, Faculty of Engineering, University of Guilan, P.O. 3756, Rasht, Guilan, Iran. ${ }^{2}$ Agricultural Department Faculty, University of Guilan, Rasht, Guilan, Iran. 
saline-sodic soils and indicated that the liquid limit decreased by $25 \%$ in average when the EC decreased from 40 to $2 \mathrm{mmohs} / \mathrm{cm}$. Anson et al. [8] carried out leaching with calcium chloride solution on the sodium kaolinite and montmorillonite clays and showed that increasing the $\mathrm{Ca}^{2+}$ concentration and replacing $\mathrm{Na}^{+}$ ions enhances the liquid limit. Also, a reduction in the residual shear strength was resulted due to the cation exchange. The effect of leaching on the properties of cemented sand deposits was examined by Ismael et al. [9]. Samples taken from two sites in Kuwait with different cementation levels were investigated. Their results indicated increased compressibility and a reduction of $c$ and $\varphi$ due to the leaching process. The leaching was examined in Strait of Canso's sediments in Canada, indicating a reduction in strength parameters, Skempton's parameter and elasticity modulus [10]. A comparative study has been made on Indian fly ash by Das [11] showing that a reduction in $\mathrm{Ca}^{2+}$ ion results in the reduction of the unconfined compressive strength and modulus of elasticity. A virgin Sabkha deposit placed in eastern Saudi Arabia was investigated by Sabtan [12]. He found that the increase in the moisture content and removal of salts from the Sabkha soil reduces the SPT $(N)$ values.

Deng and Tikalsky [13] investigated the effect of leaching on the waste foundry sand and showed that leaching and removal of the heavy metals results in a modification of some geotechnical parameters such as unconfined compressive strength and permeability.

Tran et al. [14] investigated the effect of minerals dissolution on the mechanical strength properties of sandy soils. They showed that dissolution of salts as the soluble particles fraction gives rise to a reduction in the coordination number and increasing the local voids within the mixture. These will in turn, bring about the peak shear strength to decrease, and the compressibility characteristics during direct shear loading changing from dilative to contractive state.

Asghari et al. [15] studied the geotechnical and physical properties of gypseous soils in the Southern Mashhad Metropolitan Area, Iran. Changes in the mentioned parameters were investigated through a 5-day leaching process. The results indicated that extensive dissolution and removal of gypsum bonding from soil skeleton, change soil chemical composition and therefore decrease the soil stiffness and strength parameters, accompanied by EC reduction.

Abduljauwad et al. [16] studied the leaching process on the saline soils in Persian Gulf with distilled and brackish water. They discovered that leaching with distilled water gives rise to an increase in permeability in order of $120 \%$ and $9 \%$ in constant head and falling head tests, respectively [16].

Lately, Tran et al. [14], by studying on sandy soils containing soluble mineral particles, revealed that the particle dissolution has substantial influence on the shear strength, deformation, and fabric change. However, reviewing the literature, it can be obviously understood that little attention was paid to clays while many researchers have studied sandy soils behavior. Very recently, Daraei et al. [17] elaborated on the effectiveness of different cementitious materials including cement, quicklime, gypsum, and $\mathrm{NaCl}$ in improving the geotechnical properties of problematic soils. In this paper, a series of laboratory tests were carried out to investigate the leaching-induced shear strength parameters change. For this reason, a case study was chosen to elaborate on the effect of the leaching process on the stability of a prone-to-failure existing earth slope, located adjacent to a water conveyance canal.
Fig. 1 Picture of the case study location in north Iran

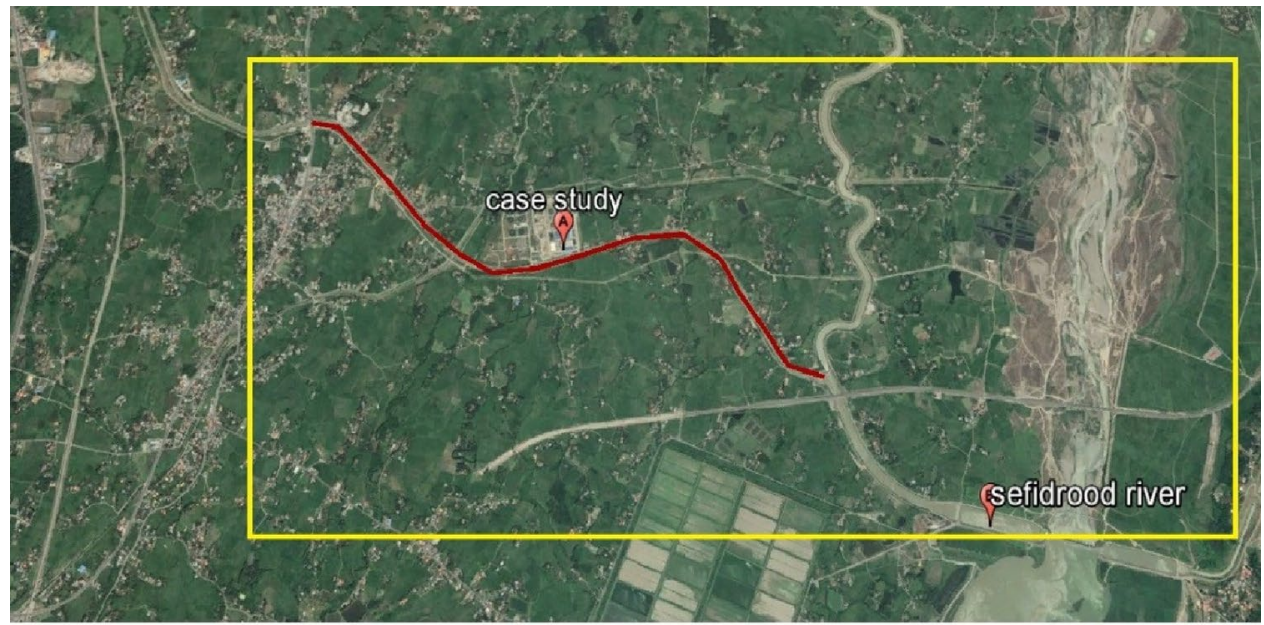




\section{Statement of the problem}

In the current study, a backfill overlooking the right Sangar's canal located in city of Rasht in north Iran was selected as a case study (Fig. 1). The right Sangar's canal plays a vital role in supplying water for both drinking and irrigation purposes. Part of its side bank slopes has undergone sliding failure which as such has led to the collapse of some concrete toe slabs as shown in Fig. 2.

\section{Experimental studies}

The clay considered in this study, was obtained from the right Sangar's canal site located in north of Iran. Physical characteristics of the soil have been presented in Table 1. Figure 3 illustrates the gradation curve for the local soil under study.

Chemical, physical and mechanical tests have been carried out to substantiate different behavioral parameters of the parent material. Table 2 illustrates a list of the experiments carried out along with the respective standards. The results of the chemical composition tests are provided in Table 3. It is noted that high concentration of $\mathrm{Na}^{+}$and $\mathrm{Cl}^{-}$is somehow reflecting the salinity of the original local soil before applied by the leaching process. Furthermore, chemical tests have been performed to determine the electrical conductivity (EC) of the host clay soil. It represents the total salts or salinity contents of the host soil.

\subsection{Electrical conductivity}

In order to determine EC according to Paye et al. [18], $500 \mathrm{~g}$ of the soil with particles finer than the sieve No. 10 was

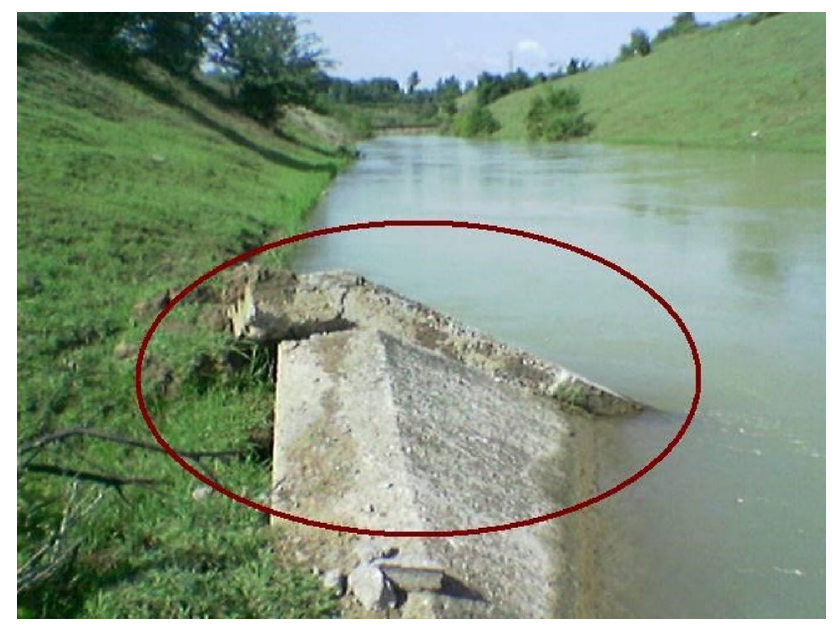

Fig. 2 The slope instability in the right Sangar's canal bank
Table 1 Index characteristics of the clay

\begin{tabular}{|c|c|c|c|c|c|}
\hline \multicolumn{3}{|c|}{ Consistency limits } & \multirow[t]{2}{*}{$D_{50}(\mathrm{~mm})$} & \multirow[t]{2}{*}{$G_{\mathrm{S}}$} & \multirow[t]{2}{*}{ Type of soil } \\
\hline LL (\%) & PL (\%) & PI (\%) & & & \\
\hline 38 & 26 & 12 & 0.03 & 2.64 & $\mathrm{CL}$ \\
\hline
\end{tabular}

saturated with distilled water. The soil was then soaked for $24 \mathrm{~h}$ to allow solubility of the total salt. Water was extracted afterward using a funnel, a filter paper, and a suction flask. Inserting electrodes in the substance in $25^{\circ} \mathrm{C}$ rendered the $\mathrm{EC}$ values. $\mathrm{EC}$ values recorded in nonstandard temperatures can be corrected from Eq. 1.

$\mathrm{EC}_{25}=\mathrm{EC}_{T}-0 / 02(T-25) \mathrm{EC}_{T}$

where $\mathrm{EC}_{T}$ indicates the electrical conductivity in temperature $T$.

Obviously, the higher the saturation level of the soil, the higher EC values are expected due to the higher solubility potential.

For the considered soil, EC was calculated 17.94 mmohs/ $\mathrm{cm}$. Then, the soil underwent the leaching process, accompanied by the salt reduction/removal from the soil structure, exhibiting noticeable $\mathrm{EC}$ reduction.

\subsection{Sample preparation}

The value of EC of the original soil was measured $17.94 \mathrm{mmohs} / \mathrm{cm}$. Then, to apply leaching, the soil was placed in a special container. The leaching process resulted in salt removal and EC reduction in the soil. The soil on the leaching process was categorized into 8 samples $(A, B, C$, $D, E, F, G, H)$ which possess different $E C$ values. Sample $A$ is the natural soil and sample $H$ is the one undergone a completed leaching operation. Soil samples as listed in Table 4 are prepared in standard proctor mold to investigate their

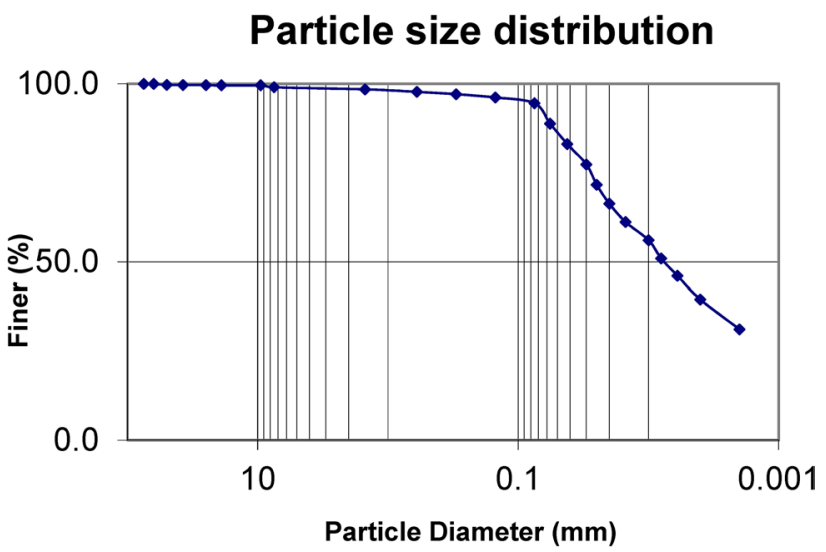

Fig. 3 Gradation curve of the soil under study 
Table 2 Physical and mechanical tests conducted

\begin{tabular}{llllll}
\hline Type of test $G_{\mathrm{S}}$ & $\begin{array}{l}\text { Void ratio and dry } \\
\text { density }\end{array}$ & Atterberg limits & Hydraulic conductivity & $\begin{array}{l}\text { Unconfined compres- } \\
\text { sive strength }\end{array}$ & Direct shear test \\
\hline Standard & ASTM D854-87 & ASTM D1556-82 & ASTM D4318-87 & ASTM D2434-87 & ASTM D2166-87 \\
\hline
\end{tabular}

Table 3 Chemical composition of the soil under study

\begin{tabular}{|c|c|c|c|c|c|c|c|}
\hline $\begin{array}{l}\mathrm{Na}+(\mathrm{meq} / 100 \mathrm{~g} \\
\text { soil) }\end{array}$ & $\begin{array}{l}\mathrm{Ca}^{2+}(\mathrm{meq} / 100 \mathrm{~g} \\
\text { soil) }\end{array}$ & $\begin{array}{l}\mathrm{Mg}^{2+}(\mathrm{meq} / 100 \mathrm{~g} \\
\text { soil) }\end{array}$ & So3 (meq/100 g soil) & $\mathrm{Cl}^{-}$(meq/100 g soil) & $\mathrm{PH}$ & $\mathrm{EC}(\mathrm{mmhos} / \mathrm{cm})$ & SAR \\
\hline 1.6 & 0.006 & 0.006 & 1.1 & 0.7 & 8.5 & 17.94 & 20.42 \\
\hline
\end{tabular}

Table 4 Test scheme adopted in the current study

\begin{tabular}{lllllllll}
\hline Samples & $A$ & $B$ & $C$ & $D$ & $E$ & $F$ & $G$ & $H$ \\
\hline Leaching time (day) & 0 & 5 & 10 & 15 & 20 & 25 & 30 & 35 \\
EC (mmohs/cm) & 17.94 & 9.12 & 7.42 & 6.45 & 2.44 & 1.78 & 0.85 & 0.72 \\
\hline
\end{tabular}

Fig. 4 UC samples prepared in different moisture contents; a dry; and $\mathbf{b}$ wet

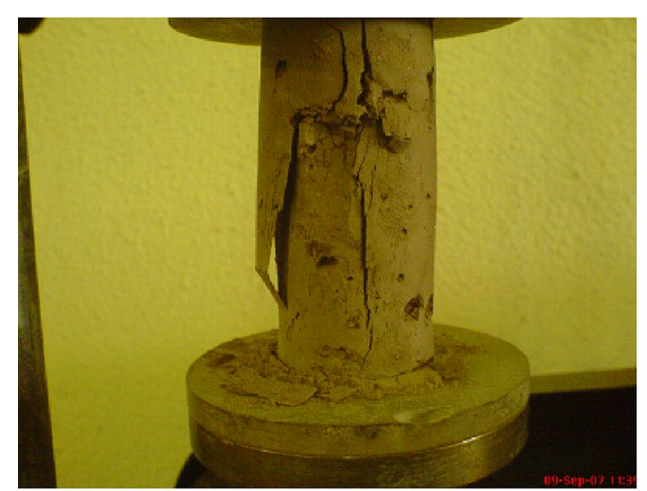

(a)

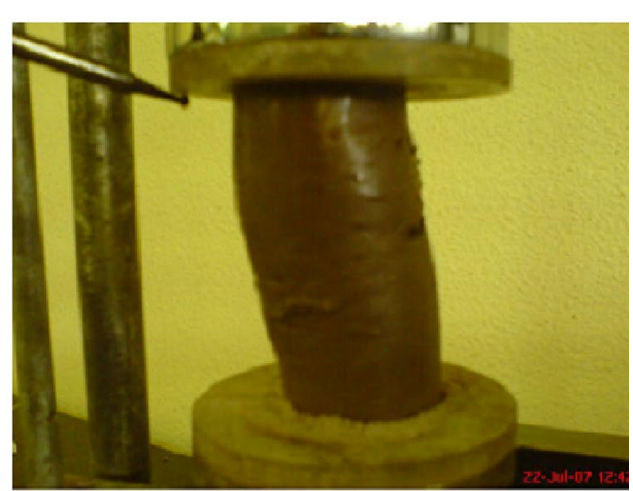

(b) compaction characteristics. Unconfined compression test samples were then prepared in optimum moisture contents. The prepared UC samples were tested under two different wet and dry conditions, but both in optimum compaction state (Fig. 4). Furthermore, standard direct shear tests were carried out on the same samples under drained and undrained conditions.

\section{Results and discussion}

As confirmed from Table 4, the leaching process gives rise to the reduction of the electrical conductivity. Having calculated parameters of the soil for each sample, changes of the parameters had been investigated and profiled due to the salt removal from the host soil. Indeed, the salt elimination through the leaching process is reflected in form of the changes in different physical and chemical parameters of the soil. Table 5 provides the effects of the salinity reduction on the physical parameters of the host soil.

Results of the unconfined compression tests on the samples undergone with the leaching process in two different dry and wet conditions are shown in Fig. 5. In general, it is observed that the unconfined compressive strength is highly correlated with the electrical conductivity of the soil samples which in turn is direct reflection of the salt content. It is further noted from Fig. 5 that the unconfined compressive strength of the samples compacted at optimum compaction state bears higher values in dry state than compacted in optimum moisture content. It is worth mentioning that the water infiltration has proven to contribute both directly and indirectly to the shear strength diminution of the host soil containing soluble minerals.

Elastic deformation modulus in unconfined condition was calculated from the unconfined compression test results and reflected in Fig. 6 for two different 
Table 5 Physical parameters variation through leaching process

\begin{tabular}{lcccccccl}
\hline Samples & $A$ & $B$ & $C$ & $D$ & $E$ & $F$ & $G$ & $H$ \\
\hline LL (\%) & 38.7 & 34.4 & 32.5 & 30.2 & 29.2 & 28.8 & 28.3 & 28 \\
PL (\%) & 26.4 & 23.1 & 22.1 & 21.1 & 20.5 & 20.2 & 19.8 & 19.4 \\
PI (\%) & 12.3 & 11.3 & 10.4 & 9.1 & 8.7 & 8.6 & 8.5 & 8.5 \\
$G_{\mathrm{s}}$ & 2.64 & 2.62 & 2.62 & 2.62 & 2.61 & 2.61 & 2.61 & 2.61 \\
$e$ & 0.60 & 0.65 & 0.70 & 0.72 & 0.75 & 0.78 & 0.8 & 0.81 \\
$\gamma_{\mathrm{d}}\left(\mathrm{g} / \mathrm{cm}^{3}\right)$ & 1.65 & 1.59 & 1.54 & 1.52 & 1.49 & 1.47 & 1.45 & 1.44 \\
$K(\mathrm{~cm} / \mathrm{s}) \times 10^{-7}$ & 2.15 & 2.28 & 2.34 & 2.98 & 3.42 & 3.91 & 4.09 & 4.23 \\
\hline
\end{tabular}

Table 6 Results of direct shear tests on the samples underwent the leaching process

\begin{tabular}{llllll}
\hline Samples & $C_{\mathrm{CU}}\left(\mathrm{kg} / \mathrm{cm}^{2}\right)$ & $\phi_{\mathrm{CU}}\left({ }^{\circ}\right)$ & $C_{\mathrm{CD}}\left(\mathrm{kg} / \mathrm{cm}^{2}\right)$ & $\phi_{\mathrm{CD}}\left({ }^{\circ}\right)$ & $\phi_{\mathrm{CU}}\left(^{\circ}\right)$ \\
\hline$A$ & 0.37 & 9.1 & 0.110 & 23.5 & 9.1 \\
$B$ & 0.31 & 6.5 & 0.070 & 20.0 & 6.5 \\
$C$ & 0.28 & 6.1 & 0.057 & 17.0 & 6.1 \\
$D$ & 0.26 & 5.5 & 0.050 & 16.5 & 5.5 \\
$E$ & 0.22 & 4.6 & 0.041 & 14.5 & 4.6 \\
$F$ & 0.19 & 4.6 & 0.037 & 14.2 & 4.6 \\
$G$ & 0.18 & 4.5 & 0.034 & 13.8 & 4.5 \\
$H$ & 0.17 & 4.5 & 0.030 & 13.3 & 4.5 \\
\hline
\end{tabular}

soil substantially declines through the infiltration of the water, resonated by dissolution of the contained salts and minerals.

Furthermore, direct shear test was opted to elaborate

Fig. 5 Unconfined compressive strength changes due to the leaching in extreme soaking states

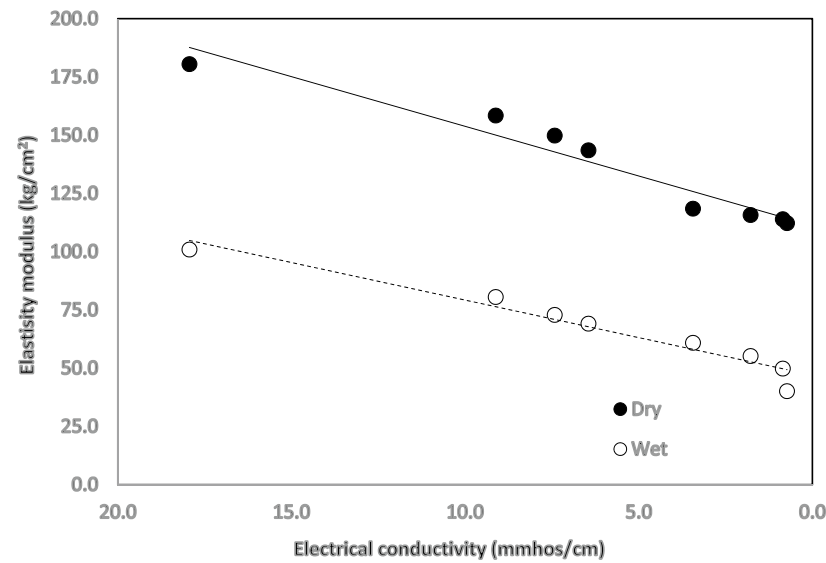

Fig. 6 Elasticity modulus changes due to the leaching process in wet and dry conditions

conditions of dry and optimum moisture content. Similar to the findings on unconfined compressive strength, it is observed that the deformation characteristics of the host on the shear strength properties changes due to the leaching process. For this reason, two different drainage conditions were adopted during the shearing process. For both sets of tests, the samples were consolidated during the overburden pressure application. Table 6 provides information on the shear strength parameters in two different drainage conditions. Drained and undrained cohesion and internal friction angle are listed in Table 6 for samples with different leaching period. It is obvious that both the shear strength parameters undergo changes with the leaching process, and indeed they decrease with the leaching time.

\subsection{Physical test results}

As presented in Table 5, leaching-induced EC reduction has led to $28.8 \%$ decrease in the liquid limit (LL) of the host soil, consistent with findings of Ismael [5], who reported 34\% reduction of $L L$ as a result of the leaching process on an $M L$ soil containing salts such as gypsum and anidride. Similar findings were reported by Guarnieri et al. [2], Sridharan et al. [7], and Anson et al. [8] as discussed earlier. Moreover, Table 5 indicates $30.7 \%$ reduction in the plasticity index (PI) of the host soil due to the leaching process and a corresponding 93\% decrease in the EC values. Furthermore, the leaching 
process in the current study led to $26 \%$ increase in the void ratio which as such resulted in $13 \%$ drop in the dry density $\gamma_{d}$ of the host soil. This phenomenon, while endorsed from Isamel [5] and Moore et al. [10], could have happened due to the fine particles being washed out from the soil skeleton and the salt crystals being solved.

Finally, the results presented in Table 5 denote an increasing hydraulic conductivity $(k)$ due to the leaching process. This behavior which was similarly reported by Al-Sanad et al. [1], and Abduljauwad et al. [16], can admittedly be attributed to the void ratio increase,

\subsection{Strength and stiffness test results}

Figure 5 shows that the leaching process brings about $46 \%$ reduction in the unconfined compressive strength of the host soil in dry optimum compaction condition. Abduljauwad et al. [16] reported similar findings on the saline silty soils in Persian Gulf due to the leaching process. Furthermore, it is obvious from Fig. 6 that the leaching-induced EC changes are accompanied by proportional variation in the modulus of elasticity. This implies that the salt removal due to the leaching process has yielded a reduction in the elastic deformation parameters.

Another observation from the strength and stiffness tests results is that pre-wetting the soil samples in optimum compaction state renders prolonged exposure time which as such gives rise to more solubility and salt removal accordingly. This implies that the reduction in strength and stiffness parameters will become more highlighted if the medium is initially sprinkled with water.

Das [11] reported that the calcium ion removal from a soil in India would result a dramatic reduction in the unconfined compressive strength and modulus of elasticity.

Table 6 further illustrates that the cohesion and internal friction angle of the host soil in both drained and undrained conditions declines with the leaching process. For this reason, the direct shear test results under consolidated drained (CD) and consolidated undrained (CU) conditions have been measured and reported in Table 6 . Such behavior might be attributed to the dry unit weight reduction and also the removal of the fine content due to the leaching phenomenon. Conversely, Guarnieri et al. [2] stated that increasing the EC values of the host soil will yield increased strength parameters which is compatible with the findings of the current study.

\section{Slope stability analyses}

Variations of the mechanical parameters of the backfill soil due to leaching process have been implemented to the stability models and slope stability analyses have been carried out.

SLOPE/W, a sub-category of GEO-SLOPE was utilized to conduct slope stability analyses. The software is based on the limit equilibrium method (LEM) which can suggest the critical slope surface and the minimum safety factor against the sliding failure.

In this study, slope stability analyses were carried out by solely considering Janbu, Ordinary and Bishop's algorithms as adopted by Lebron et al. [7]. Table 7 shows the underlying strength and stiffness properties of the soil layers constituting the slope under study.

Figure 7 illustrates the layering scheme of the slope under study. It is observed that two medium clay layers overlie a sand deposit. As expected, in undisturbed conditions, the sloping ground seems stable; however, the leaching process as discussed earlier will be shown to alter the stability state of the natural slope due to the imposed changes in the shear strength and stiffness parameters. Indeed, the diminution of the shear strength parameters are finally translated into faltering stability condition slopes which are more prone to sliding failure.

An initial slope stability analysis through LEM formulations of SLOPE/W yielded safety factor of 1.125 as noted from Fig. 8. As apparent from this figure, vertical slice method has been adopted and grid of the potential sliding circle's centers has been patterned to seek for the optimum stability condition in LEM formulations.

Evaluation of the short-term stability condition of the slope under study can be achieved by indirectly making estimation of the undrained shear strength properties from the EC values of the in situ soil. For this reason, the linear correlations delineated in Fig. 5 yields $q_{u}$ value by assuming $17.94(\mathrm{mmohs} / \mathrm{cm})$ for the initial EC value as listed in Table 3. Implementing the correlated undrained shear strength to the slope stability analysis package suggests FS value of 1.198 as shown in Fig. 9. It is observed that the slope under study bears slightly higher safety factor in undrained condition. This means that its long-term stability condition is more critical.

Table 7 Drained mechanical parameters of the clay layers

\begin{tabular}{llllll}
\hline Depth $(\mathrm{m})$ & Type of soil & $C\left(\mathrm{~kg} / \mathrm{cm}^{2}\right)$ & $\varphi\left({ }^{\circ}\right)$ & $\gamma\left(\mathrm{kg} / \mathrm{cm}^{3}\right)$ & $E_{\mathrm{S}}\left(\mathrm{kg} / \mathrm{cm}^{3}\right)$ \\
\hline $0-13$ & $\mathrm{CL}$ & 0.400 & 17 & 1.94 & 1800 \\
$13-24$ & $\mathrm{CL}$ & 0.395 & 19 & 1.90 & 1500 \\
$24-28$ & $\mathrm{SP}$ & 0.395 & 19 & 1.88 & 1200 \\
\hline
\end{tabular}


Fig. 7 Initial model of backfill overlooking the Sangar's right canal
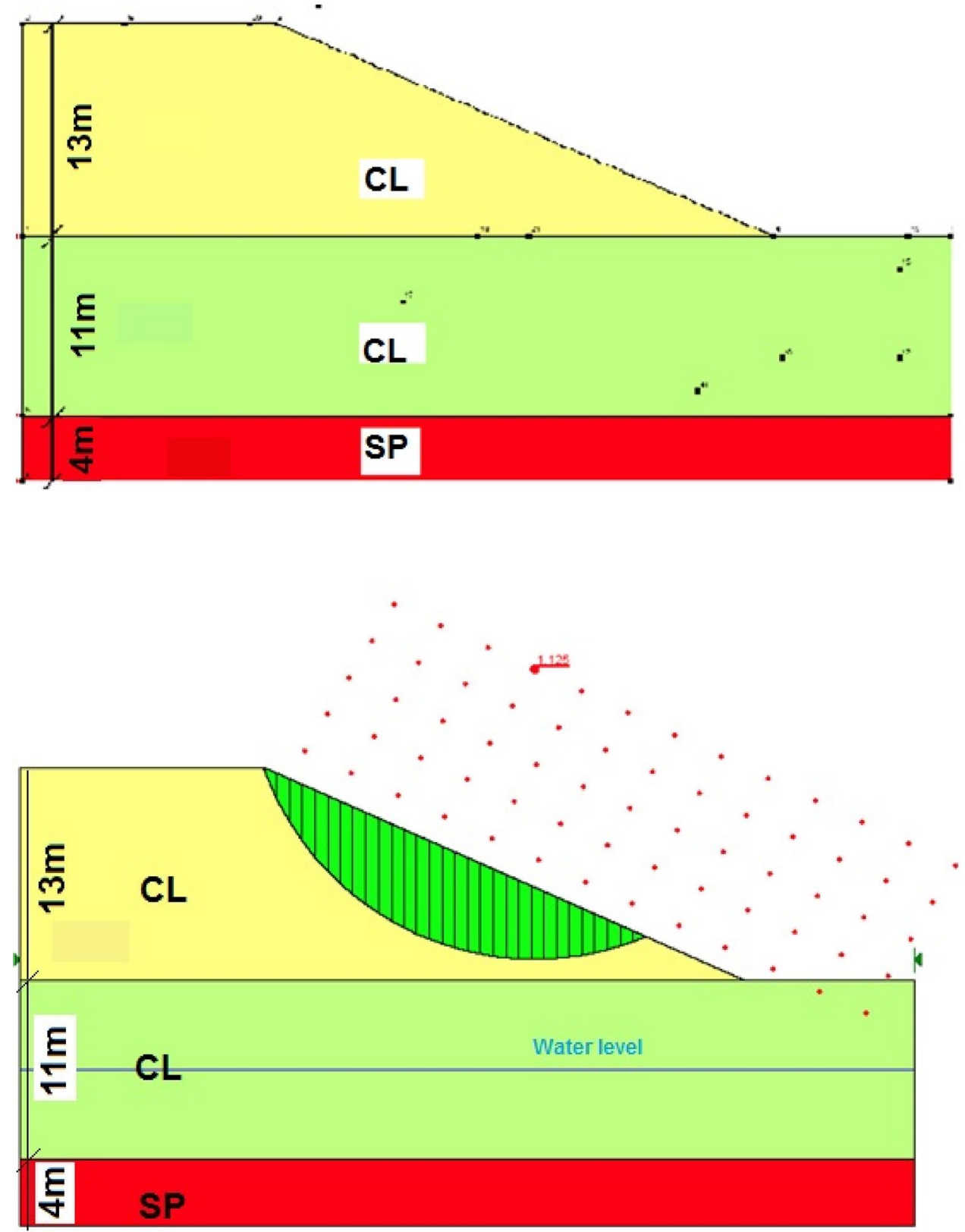

Fig. 8 Initial slope stability analysis model
The influence of the leaching process on the slope stability safety is elaborated by conducting slope stability analyses in different electrical conductivity performances. Indeed, the EC parameter diminishes from its initial value of $17.94 \mathrm{mmohs} / \mathrm{cm}$ to the extreme condition of $0.722 \mathrm{mmohs} / \mathrm{cm}$ due to the leaching phenomenon. This is accompanied by the shear strength reduction as addressed earlier in the form of correlation between the unconfined compressive strength and the electrical conductivity values at different leaching states.

Figure 10 shows the FS value for the slope under study at extreme leaching condition as denoted in Table 4 by the " $H$ " designation.
Figure 11 illustrates the safety factor variation against the EC variation. It is observed that almost $100 \%$ leachinginduced reduction in the electrical conductivity would lead to about $25 \%$ decline in the safety factor against sliding. In secondary axis, the corresponding values of the unconfined compressive strength are drawn for further comparisons. The linear variation of FS with the electrical conductivity of the soil undergoing the leaching process signifies that the sliding safety factor is linearly proportional with the soil undrained shear strength which is obvious according to Jamshidi Chenari et al. [19].

As noted from Table 6, results of the direct shear tests have been translated into the shear strength parameters 
Fig. 9 Undrained slope stability analysis in natural state based on the unconfined compression test results
Fig. 10 Undrained slope stability analysis after leaching phenomenon
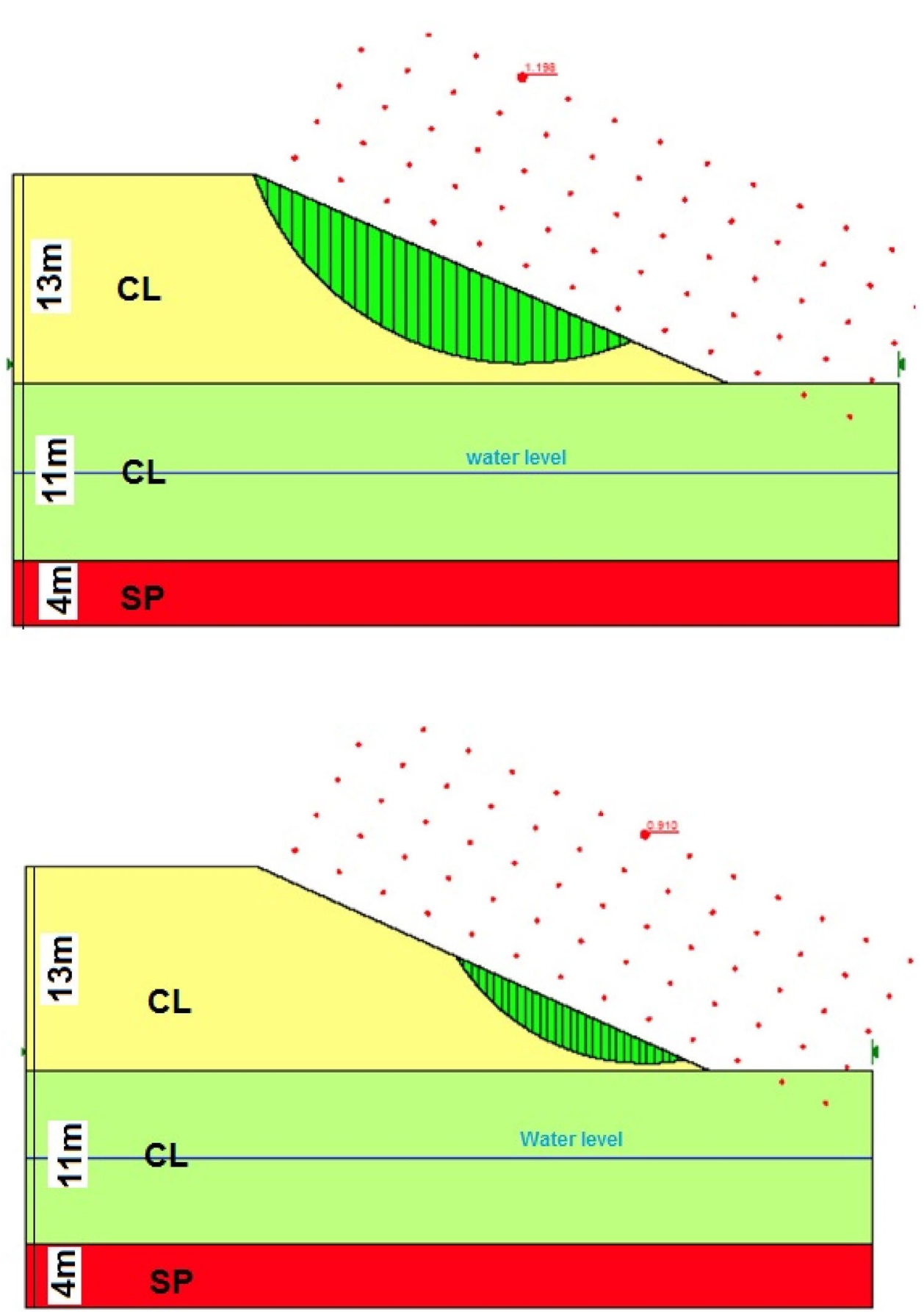

in two different drainage conditions. Figure 12 illustrates variations of the sliding safety factor against the leachinginduced EC reduction for drained and undrained conditions. It is observed that in both the drainage conditions, leaching process leads to almost 50\% safety reduction at limit. Another observation from the results shown in Fig. 12 is that the leaching-induced strength reduction becomes less highlighted in undrained loading scheme when compared to the drained condition. This can presumably lend support to the contention that the leaching phenomenon reduces the coordination number in host soil as pointed out by Tran et al. [14]. Reduction of the drained internal friction angle is therefore resulted as notable from Table 6 , which in turn translates into more diminished slope safety. 


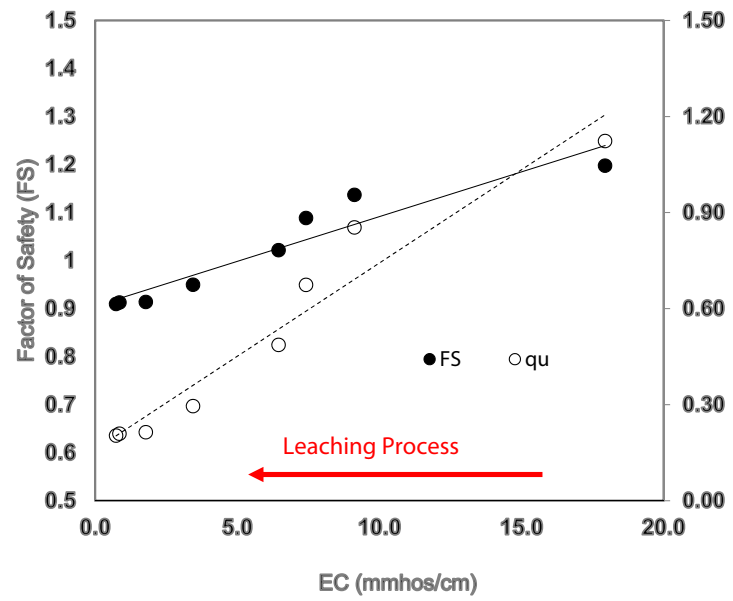

Fig. 11 Variation of the undrained sliding safety factor due to the pre-wetted leaching-induced EC reductions using unconfined compression test results

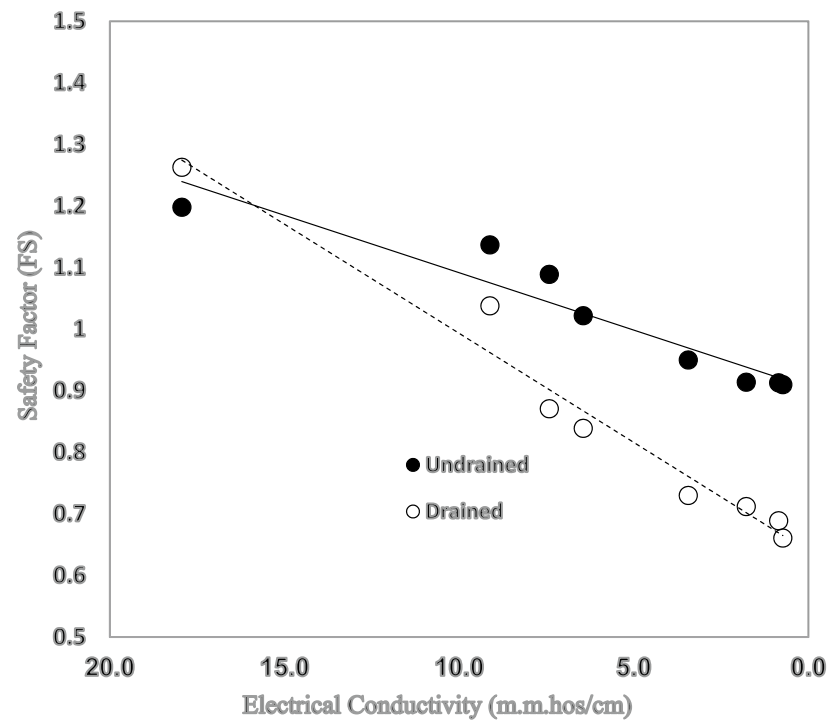

Fig. 12 Variation of the sliding safety factor due to leachinginduced EC reduction using the direct shear tests results

\section{Stabilization scheme}

Jamshidi Chenari et al. [20] proved efficiency of the Vetiver planting in soil improvement plans, especially when dynamic and cyclic loading is concerned. Figure $13 \mathrm{dem}$ onstrates the original planting scheme which was aimed to stabilize the side slopes along with a photograph of its current developed status. Planting indeed plays a dual role by both the rooting effect which introduces local reinforcement to the underlying soil, rendering erosion resistance to the host soil, and infiltration impediment by the shielding effect of the canopy of dense leaves

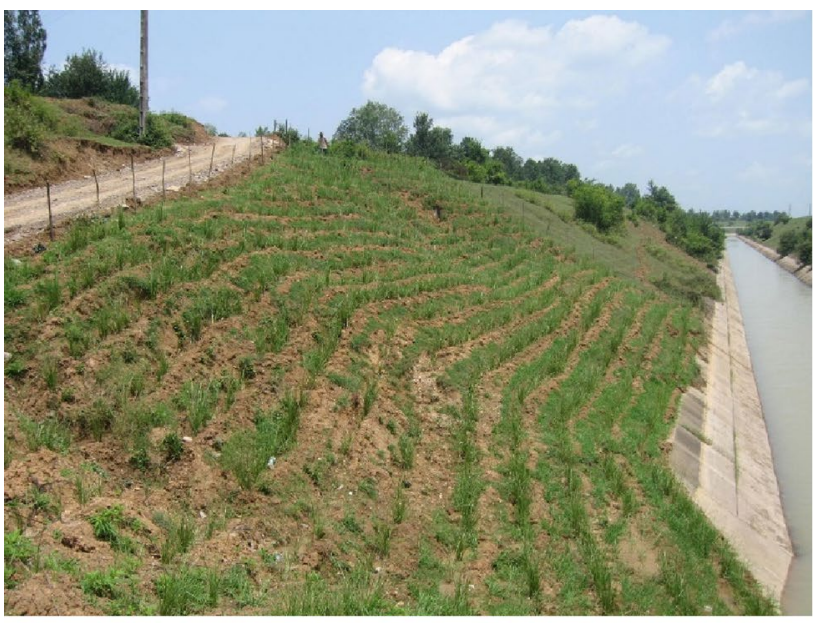

(a)

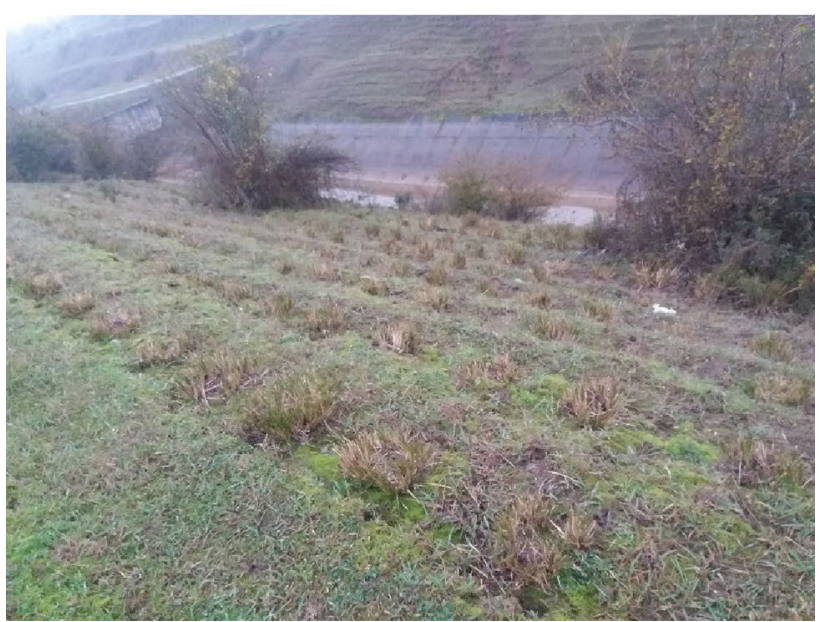

(b)

Fig. 13 Stabilization of the instable slope by Vetiver plantation; a initial planting; and $\mathbf{b}$ current status

of the Vetiver plant. This brilliant stabilization scheme was accompanied by some toe stabilization provisions like concrete slabs and gabion as appears from Fig. 13. This synergy would render additional effectiveness to the local soil improvement plan.

\section{Conclusion}

A leaching process was applied to a pure $\mathrm{CL}$ clay to investigate its effect on the physical and mechanical properties of the soil undergoing dissolution phenomenon. Due to the chemical composition relevant to the soil under study, the leaching was conceived to wash out the high salt content leading to the diminution of the soil strength parameters in both short- and long-term conditions. The leaching-induced strength parameters reduction was 
elaborated through interpretations of unconfined compression and direct shear experiments. The implication of this reduced-form strength parameters on the stability analysis of a case study slope was studied by carrying out some LEM slope stability analyses. Following results and conclusions were made through comparison of the experimental and numerical analyses results.

- Leaching of salts in CL clay leads to the chemical materials dissolution and bonds removal from the soil fabric and increasing the void spaces.

- Increasing the void ratio owing to the leaching process causes porosity formation which is in effect translated into the augmented volume-compressibility and permeability characteristics.

- The unconfined compressive strength and the elasticity modulus was shown to diminish with the leaching process.

- Leaching process was observed to decreases the cohesion and internal friction angle in both drained and undrained conditions.

- Shear strength parameters reduction due to the leaching process results in undermining the safety of slopes against sliding, substantiated in form of reduced safety factors.

- Leaching process in pre-wet condition was proven to be more influential due to the extended exposure time which is important for fine-grained soils due to their water affinity.

\section{Compliance with ethical standards}

Conflict of interest On behalf of all authors, the corresponding author states that there is no conflict of interest.

\section{References}

1. Al-Sanad H, Al-Bader B (1990) Laboratory study on leaching of calcareous soil from Kuwait. J Geotech Eng 116(12):1797-1809

2. Guarnieri A, Fabbri A, Molari G (2005) Influence of sodicity and salinity on the mechanical properties of two Italian soils. Biosyst Eng 91(2):239-243
3. Mitchell JK (1992) Fundamentals of soil behaviour, 2nd edn. University of California, Berkeley

4. Al-Amoudi OSB, Abduljauwad SN (1994) Shear strength characteristics of sabkha soils. J Geotech Eng 120(11):654-663

5. Ismael NF (1993) Laboratory and field leaching tests on coastal salt-bearing soils. J Geotech Eng 119(3):453-470

6. Sridharan A, Rao SM, Gajarajan VS (1987) Influence of fluoride on the compressibility of montmorillonites. Geotechnique 37(2):197-206

7. Lebron I, Suarez DL, Alberto F (1994) Stability of a calcareous saline-sodic soil during reclamation. Soil Sci Soc Am J 58(6):1753-1762

8. Anson RWW, Hawkins AB (1998) The effect of calcium ions in pore water on the residual shear strength of kaolinite and sodium montmorillonite. Geotechnique 48(6):787-800

9. Ismael NF, Mollah MA (1998) Leaching effects on properties of cemented sands in Kuwait. J Geotech Geoenviron Eng 124(10):997-1004

10. Moore JG, Brown JD, Rashid MA (1977) The effect of leaching on engineering behaviour of a marine sediment. Géotechnique 27(4):517-531

11. Das SK (2006) Geotechnical properties of low calcium and high calcium fly ash. Geotech Geol Eng 24(2):249-263

12. Sabtan AA (2005) Performance of a steel structure on Ar-Rayyas Sabkha soils. Geotech Geol Eng 23(2):157-174

13. Deng A, Tikalsky PJ (2008) Geotechnical and leaching properties of flowable fill incorporating waste foundry sand. Waste Manag 28(11):2161-2170

14. Tran MK, Shin H, Byun YH, Lee JS (2012) Mineral dissolution effects on mechanical strength. Eng Geol 125:26-34

15. Asghari S, Ghafoori M, Tabatabai SS (2018) Changes in chemical composition and engineering properties of gypseous soils through leaching: an example from Mashhad, Iran. Bull Eng Geol Environ 77(1):165-175

16. Abduljauwad SN, Al-Amoudi OSB (1995) Geotechnical behaviour of saline sabkha soils. Geotechnique 45(3):425-445

17. Daraei A, Sherwani AFH, Faraj RH, Mohammad S, Kurdo S, Zare S, Mahmoodzadeh A (2019) Stabilization of problematic soil by utilizing cementitious materials. Innov Infrastruct Solut 4(1):33

18. Paye AL, Miller RH, Keeny DR (1984) Methods \& soil analysis, part I. SSSA Inc., Madison, WI

19. Jamshidi Chenari R, Zamanzadeh M (2016) Uncertainty assessment of critical depth of vertical unsupported cuts in undrained clay using random field theory. Sci Iran Trans A Civ Eng 23(3):864-875

20. Jamshidi Chenari R, Soltankhah Pishkhani S, Karimpour Fard M, Shamsi Sosahab J (2018) Experimental and numerical investigation of dynamic properties of soil stabilized by young Vetiver. Ital Geotech J 52(1):49-58

Publisher's Note Springer Nature remains neutral with regard to jurisdictional claims in published maps and institutional affiliations. 